\title{
Development of Biodegradable Plastic as Mango Fruit Bag
}

\author{
Andres M. Tuates Jr.", Ofero A. Caparino* \\ \# Philippine Center for Postharvest Development and Mechanization \\ CLSU Compound, Science City of Muñoz, Nueva Ecija.3120. Philippines \\ E-mail: amtuates@yahoo.com
}

\begin{abstract}
Plastics have achieved a dominant position in agriculture because of their transparency, lightness in weight, impermeability to water and their resistance to microbial attack. It is use as food and fruits packaging, fruit bag, food container, seedling bag, mulching film, protective for greenhouse, dryer shed and among others. However, this generates higher quantity of wastes that are difficult to dispose by farmers. The plastic residues remain on the soil for some years as large pieces and they are impediment to plant growth and also a potential hazard to animals if the land is subsequently put down to grass. To address these problems, the project aim to develop and evaluate the biodegradable film for mango fruit bag during development. Cassava starch and polybutylene succinate (PBS) was used in the development biodegradable film. The PBS and starch was melt-blended in a twinscrew extruder and then blown into film extrusion machine. The physic-chemical-mechanical properties of biodegradable fruit bag were done following standard methods of test. Field testing of fruit bag was also conducted to evaluate its durability and efficiency field condition. The PHilMech-FiC fruit bag is made of biodegradable material measuring 6 x 8 inches with a thickness of 150 microns. The tensile strength is within the range of LDPE while the elongation is within the range of HDPE. However, it has higher density, thickness swelling and absorbed more water. It is projected that after thirty six (36) weeks, the film will be totally degraded. Results of field testing shows that the quality of harvested fruits using PHilMech-FiC biodegradable fruit bag in terms of percent marketable, non-marketable and export, peel color at ripe stage, flesh color, TSS, oBrix, percent edible portion is comparable with the existing bagging materials such as Chinese brown paper bag and old newspaper.
\end{abstract}

Keywords - cassava starch; PBS; biodegradable; chemical and mechanical properties.

\section{INTRODUCTION}

Plastics have achieved a dominant position in agriculture, this is a direct consequence of their transparency, lightness in weight, impermeability to water and their resistance to microbial attack [1].

Disposal and proper management of agricultural waste is currently a big concern not only in the country but worldwide. Although there are existing recycling plants in the country that process the plastic waste, mechanical recycling may actually consume more energy in the long term than making the same product from virgin polymers. Likewise, the plastic residues remain on the soil for some years as large pieces and are not only an impediment to plant growth but also a potential hazard to animals if the land is subsequently put down to grass [2].

On the other hand, mango industry in the Philippines is looking for plastic based materials that could be used as bagging materials in all weather conditions. Because, the most commonly used bagging materials in the country are newspaper which could not withstand strong winds and heavy rainfall that destroy the bags hence, greater chances for the insects to damage during fruit development stage [3].

One way of solving the problem created by the plastic industry and to address the needs of the mango growers is the use of biodegradable plastic materials. Biodegradable plastic are the kind of polyolefin plastic which are created using materials that allow the bag to complete decompose after a period of time by the action of naturally-occurring microorganisms such as bacteria, fungi, or controlled degradation though the incorporation of prodegradant to undergo accelerated oxidative define degradation initiated by natural light, heat and oxygen. Many efforts have been exerted to develop bio-based polymers for conserving the petrochemical resources and reducing environmental impact. Among of them are, bio-based polymer made from sago derived from starch and natural fiber [4], disposable foamed food containers using starch and nanoclay [5], biodegradable from cassava starch [1], mulching film made of corn starch and oil derivatives [6] and bio bag made of corn starch [7].

Starch-based completely biodegradable polymers (SCBP) are promising materials for various applications and their development is a good solution for reducing the consumption of petroleum resources and environmental 
problem [8]. They are disintegrated totally within 3 months to 5 years [9][10][11][12].

One of the potential biodegradable plastic material is the blending of cassava starch and Polybutylene succinate (PBS). Cassava starch is inexpensive and considered waste in the chips processing, widely available and relatively easy to handle while PBS is one of the most promising biodegradable aliphatic polyesters, with desirable properties such as biodegradability, melt process ability, and both thermal and chemical resistance [13].

Therefore, it is necessary to developed a biodegradable plastic material that technically viable and subsequently reduce the use of plastic based in agriculture, particularly mango production.

\section{MATERIALS AND METHOD}

Cassava starch was blended with Polybutylene succinate (PBS) in the development biodegradable film.

\section{A. Preparation and formulation of biodegradable film}

The biodegradable pellet and fruit bag were produced at D and L Color, Cabuyao, Laguna. The PBS and starch was melt-blended in a twin-screw extruder. The melted blends were emerged in the form of continuous strands through the die. The strands were cooled using water tank and pelletized. The pellets were then blown into 150 microns thick films using single screw blown film extrusion machine.

\section{B. Characterization of the chemical properties of biodegradable film}

Three levels of percentage of cassava starch were blended in the PBS for the characterization of the chemical properties of biodegradable film. The chemical properties of PHilMech-FiC biodegradable film was characterized using Fourier Transform Infrared (FTIR) spectroscopy and Atomic Force Microscope (AFM).

1) Fourier Transform Infrared (FTIR) spectroscopy: The functional groups present in the polymer product were determined using IR Prestige 21 Fourier Transform Infrared Spectrophotometer. The sample was scanned for 10 times from 4000 to $600 \mathrm{~cm}-1$. FTIR analysis was also used to probe the occurrence polymerization reaction of the polymers.

2) Atomic Force Microscope (AFM): Imaging was done using XE 70 Park System Atomic Force Microscope in Noncontact mode with Nanosensors ${ }^{\mathrm{TM}}$ Point Probe ${ }^{\circledR}$ Plus cantilever (resonant frequency of $330 \mathrm{kHz}$ with nominal spring constant of $42 \mathrm{~N} / \mathrm{m}$ ). The scanner was calibrated following the standard procedure of the manufacturer. Samples were dispersed in absolute ethanol and were deposited in clean freshly cleaved mica sheets and air dried for one (1) hour. The deposited samples were then washed several times with de-ionized water and then absolute ethanol and were allowed to air dry for another hour. All analysis was conducted at $25^{\circ} \mathrm{C}$.

\section{Production of PHilMech-FiC biodegradable fruit bag}

Fifteen percent of the cassava starch was blended to the PBS for the production of biodegradable. Likewise, the physic-mechanical properties such as density, water absorption, tensile strength, elongation and thickness swelling of the biodegradable film were measured and evaluated.

1) Density: The density of the biodegradable film was determined based on ISO 1183 (ASTM D792) method of test.

2) Water absorption: The water absorption of biodegradable film was determined based on ISO 62 (ASTM-D570) method of test.

3) Water absorption: The water absorption of biodegradable film was determined based on ISO 62 (ASTM-D570) method of test.

4) Tensile strength and elongation: The tensile strength and elongation of biodegradable film was tested using universal testing machine (INSTRON model). The samples were formed into dumb bell shapes with gage length of 150 $\mathrm{mm}(50 \mathrm{~mm}$ longer than the initial grip separation as per standard), width of $12.7 \mathrm{~mm}$ along the test area, width of $25.4 \mathrm{~mm}$ near the grips, and thickness of $0.15-0.20 \mathrm{~mm}$ as per specimen. The thickness of the specimens was noted before each trial was conducted. The initial grip separation used was $100 \mathrm{~mm}$ and the rate of grip separation was 50 $\mathrm{mm} / \mathrm{min}$. Standard operating procedure was employed at normal room condition $\left(73^{\circ} \mathrm{F}, 50 \% \mathrm{RH}\right)$.

\section{Biodegradability of PHilMech-FiC fruit bag}

The biodegradability or capability of the biodegradable fruit bag to undergo decomposition in a specified period of time was investigated under natural soil burial test at PHilMech compound. The biodegradation rate of the materials was observed each week within a period of seventeen weeks. The weight of the specimens was recorded at regular time interval.

\section{E. Field testing and evaluation}

The performance testing and evaluation was conducted at the orchard of the National Mango Research and Development Center (NMRDC), San Miguel, Jordan, Guimaras.

1) Description of the Bagging materials: Table I shows the description of bagging materials for mango fruits. The PHilMech-FiC fruit bag is made of biodegradable material measuring $6 \times 8$ inches with a thickness of 150 microns. Local newspapers was made into rectangular bag and measured 5.5x8 inches with both sides folded and fastened with staple wire. On the other hand, Chinese brown paper bag is pre-manufactured in China. It is made of brown waxy paper with carbon linings inside, rectangular (7x10 inches) and with a thin wire on the upper right portion of the bag which is tied around the fruit pedicel.

2) Test trees: Five physiologically matured grafted mango trees (12 years old) were induced to flower using $1.50 \%$ potassium nitrate $(\mathrm{KNO} 3)$. A follow-up spray was conducted three days after the 1st induction to insure high flowering intensity of the trees. Developing flowers and fruits were protected from major pests by spray application of insecticides and fungicides as needed. Foliar fertilization was done to enhance flower and fruit development. 
Irrigation and field sanitation through under brushing was also undertaken. The fruits of mango test trees were bagged using PHilMech-FiC fruit bag, local newspapers and Chinese brown waxy paper bag at 50 to 55 days after flower induction (DAFI) [10].

TABLE I

DESCRIPTION OF BAGgING MATERIALS For MANGO Fruits

\begin{tabular}{|l|l|c|l|}
\hline \multicolumn{1}{|c|}{ Treatment } & \multicolumn{1}{|c|}{ Material } & $\begin{array}{c}\text { Size } \\
\text { (inche } \\
\text { s) }\end{array}$ & \multicolumn{1}{|c|}{$\begin{array}{c}\text { Mode of } \\
\text { Enclosure }\end{array}$} \\
\hline $\begin{array}{l}\text { PhilMech-FiC } \\
\text { bag }\end{array}$ & $\begin{array}{l}\text { Biodegradable } \\
\text { film }\end{array}$ & $6 \times 8$ & Staple wire \\
\hline $\begin{array}{l}\text { Local } \\
\text { newspaper }\end{array}$ & $\begin{array}{l}\text { Rectangular paper } \\
\text { bag }\end{array}$ & $\begin{array}{c}5.5 \times \\
8\end{array}$ & Staple wire \\
\hline $\begin{array}{l}\text { Chinese brown } \\
\text { paper bag }\end{array}$ & $\begin{array}{l}\text { Brown thin waxy } \\
\text { paper with carbon } \\
\text { lining }\end{array}$ & $7 \times 10$ & $\begin{array}{l}\text { Provided } \\
\text { with wire to } \\
\text { secure and } \\
\text { enclose }\end{array}$ \\
\hline $\begin{array}{l}\text { Control (Un- } \\
\text { bag) }\end{array}$ & \multicolumn{1}{|c}{-} & \multicolumn{2}{|c}{} \\
\hline
\end{tabular}

3) Test trees: Five physiologically matured grafted mango trees (12 years old) were induced to flower using $1.50 \%$ potassium nitrate (KNO3). A follow-up spray was conducted three days after the 1st induction to insure high flowering intensity of the trees. Developing flowers and fruits were protected from major pests by spray application of insecticides and fungicides as needed. Foliar fertilization was done to enhance flower and fruit development. Irrigation and field sanitation through under brushing was also undertaken. The fruits of mango test trees were bagged using PHilMech-FiC fruit bag, local newspapers and Chinese brown waxy paper bag at 50 to 55 days after flower induction (DAFI) [10].

4) Yield: At harvest, bagged samples were counted, weighed and segregated into small (190 to $240 \mathrm{~g}$ ), medium (241 to $289 \mathrm{~g}$ ) and large (>290 g).

5) Fruit quality: The external (peel color from harvest and ripe stage) and internal characteristics (flesh color, total soluble solids and percent edible portion) of the bagged mango fruits were recorded and examined individually using National Seed Industry Council (NSIC) evaluation index for 'Carabao' mango.

\section{F. Experimental Design}

The data gathered was consolidated and analyzed using complete randomized design. ANOVA table was utilized to determine the level of significant among treatments. The difference among means was analyzed using DMRT.

\section{RESULTS AND DISCUSSION}

\section{A. Optimization of the chemical properties of biodegradable film}

1) Fourier Transform Infrared (FTIR) spectra: Table II shows the summary of peaks and FTIR spectra of biodegradable film. The intense peak at 2940 to $2850 \mathrm{~cm}-1$ and $1700 \mathrm{~cm}-1$ correspond to $\mathrm{C}-\mathrm{H}$ stretching vibrations and $\mathrm{C}-\mathrm{O}$ stretch of carbonyl group in the Polybutylene succinate, respectively. The 1330 to $1050 \mathrm{~cm}-1$ peak in PBS were due to the C-O stretching in the shifted peak of PBS-Starch Film. The shifting indicates the hydrogen bonding of the complex formed after melt blending of PBS and Starch.

TABLE II

FTIR PEAKS OF PBS AND PBS-STARCH FILM

\begin{tabular}{|c|c|c|c|c|c|}
\hline $\begin{array}{l}\text { PEAK } \\
\mathrm{cm}^{-1}\end{array}$ & Functional Group & PURE PBS & $\begin{array}{c}\text { TPS } \\
(15 \%)\end{array}$ & $\begin{array}{c}\text { TPS } \\
(20 \%)\end{array}$ & $\begin{array}{c}\text { TPS } \\
(25 \%)\end{array}$ \\
\hline $2940-2850$ & C-H Stretch & (2) & (2) & (2) & (2) \\
\hline 1700 & $\mathrm{C}=\mathrm{O}$ Stretch, Carbonyls & (2) & (2) & (2) & (2) \\
\hline $1330-1050$ & $\mathrm{C}-\mathrm{O}$ stretch & (2) & $\mathfrak{x}$ & $\mathbb{x}$ & $\mathfrak{x}$ \\
\hline $1300-1050$ & $\mathrm{C}-\mathrm{O}$ stretch & $\mathfrak{x}$ & (2) & (2) & (2) \\
\hline
\end{tabular}

2) Atomic Force Microscope Modulus Image: Figures 1a, $1 \mathrm{~b}$ and 1c show the AFM modulus images of PHilMech-FiC biodegradable fruit bag. The nodular structure with small globular entities was ranging from 13 to $22 \mathrm{~nm}$ in diameter. The modulus map also emphasized separated softer and stiffer phases assigned to amorphous and organized structures containing crystallites. Reducing the amount of starch in the biodegradable film facilitated dispersal of starch inside the polymer matrix and inhibits agglomeration of the filler. On the other hand, increasing the amount of starch facilitated water absorption.
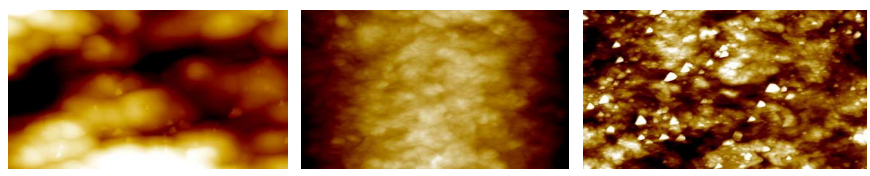

Fig. 1 Atomic Force Microscopy Images of biodegradable film at Fifteen micrometer $15 \%$ Starch (a), 20\% Starch (b) and 25\% Starch (c)

\section{B. Description of the PHilMech-FiC biodegradable fruit bag}

The PHilMech-FiC fruit bag is made of cassava starch and polybutylene succinate (PBS). It measured $6 \times 8$ inches and with a thickness of 150 microns (Fig. 2). The biodegradable fruit bag was developed using a twin-screw extruder and blown film extrusion machine.

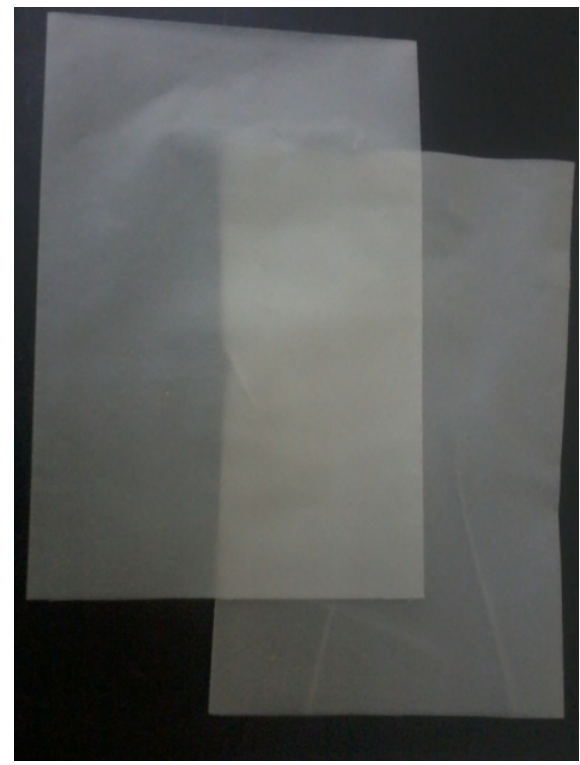

Fig. 2 PhilMech-FiC biodegradable fruit bag 
C. Physic-mechanical properties of PHilMech-FiC biodegradable fruit bag

Table III shows the physic-mechanical properties of PHilMech-FiC biodegradable film compared with the low density polyethylene (LDPE) and high density polyethylene (HDPE). The density, water absorption, thickness swelling, tensile strength and percent elongation obtained were 1.40 $\mathrm{g} / \mathrm{cc}, 4.70 \%, 5.88 \%, 8.73 \mathrm{MPa}$ and $188 \%$, respectively. The tensile strength is within the range of LDPE while the percent elongation is within the range of HDPE. HDPE and LDPE can be used as packaging, plastic film sheets, containers and among others. Moreover, PHilMech-FiC fruit bag has higher density, thickness and absorbed more water that help to facilitates degradability.

TABLE III

Physico-Mechanical Properties Of PhILMECH-Fic Biodegradable FILM

\begin{tabular}{|l|c|c|c|}
\hline $\begin{array}{c}\text { Physic-mechanical } \\
\text { properties }\end{array}$ & $\begin{array}{c}\text { PHilMech- } \\
\text { FiC film }\end{array}$ & LDPE & HDPE \\
\hline Density, g/cc & $1.38-1.40$ & $0.91-0.94$ & $0.94-0.96$ \\
\hline Water absorption, \% & $3.89-4.70$ & 1.0 & 1.0 \\
\hline Thickness & $5.26-5.88$ & - & - \\
swelling, \% & & & $21.37-$ \\
\hline Tensile strength, & $7.50-8.73$ & $4.13-$ & 37.92 \\
MPa & & 15.86 & $100-130$ \\
\hline Elongation, \% & $120-188$ & $100-650$ & \\
\hline
\end{tabular}

\section{Biodegradability of PHilMech-FiC fruit bag}

Figure 3 shows the biodegradability of the PHilMech-FiC biodegradable fruit bag and the image before and after burial test. After 17 weeks or more than two months of burial test, almost 50 percent of the biodegradable film was degraded. The rate of degradation was almost three percent per week. After 36 weeks or nine months, the PhilMech-FiC biodegradable will be totally degraded.

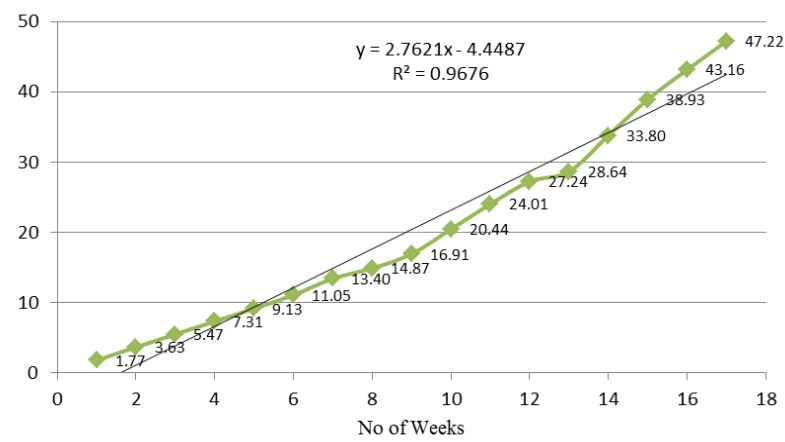

Fig. 3. Biodegradability of PHilMech-FiC biodegradable fruit bag

\section{E. Field testing and evaluation}

1) Fruit size: Table IV presented the harvested fruits classified into large (290g and up), medium (241 to $289 \mathrm{~g}$ ) and small (190 to $240 \mathrm{~g}$ ). The bagged fruit were classified as medium to large size while most of the unbag fruits were classified as small size.
TABLE IV

Classification OF Marketable Fruits OF 'CARABaO’ Mango

\begin{tabular}{|l|c|c|c|}
\hline \multirow{2}{*}{ Treatment } & \multicolumn{3}{|c|}{ Percent distribution of fruit size } \\
\cline { 2 - 4 } & Small & Medium & Large/XL \\
\hline $\begin{array}{l}\text { PhilMech-FiC } \\
\text { bag }\end{array}$ & $31.07 \pm 19.66^{\mathrm{a}}$ & $49.90 \pm 2.28^{\mathrm{a}}$ & $19.17 \pm 17.60$ \\
\hline Old Newspaper & $\begin{array}{c}40.65 \pm 24.94 \\
\mathrm{ab}\end{array}$ & $\begin{array}{c}51.70 \pm 18.62 \\
\mathrm{a}\end{array}$ & $7.64 \pm 7.40$ \\
\hline $\begin{array}{l}\text { Chinese brown } \\
\text { paper bag }\end{array}$ & $\begin{array}{c}48.92 \pm 19.22 \\
\mathrm{ab}\end{array}$ & $25.53 \pm 5.53^{\mathrm{b}}$ & $25.53 \pm 22.90$ \\
\hline Un-bag (control) & $80.78 \pm 13.37^{\mathrm{b}}$ & $15.05 \pm 7.82^{\mathrm{b}}$ & $4.17 \pm 5.89$ \\
\hline
\end{tabular}

Means not sharing letter in common differ significantly at 0.05 level of significance by DMRT

2) Fruit Quality : The external and internal characteristics of the bagged mango fruits were examined individually using National Seed Industry Council (NSIC) evaluation index for 'Carabao' mango (Table V).

The color of bagged fruits, except for Chinese brown paper bags at harvest showed green peel color while un-bag exhibited dark green peel color. This can be associated to the thin waxy material with carbon lining inside, thus, light cannot penetrate and reach the fruit and no protection of fruit to solar radiation. Likewise, peel color at ripening exhibited yellow to orange yellow and no shrinkage on the external appearance of the fruits. On the other hand, the characteristics flesh color, total soluble solids (oBrix) and (\% EP) were taken 8 days after harvest. No variation on flesh color and percent edible portion were observed on bagged and un-bag fruits.

TABLE V

EXTERNAL AND INTERNAL CHARACTERISTICS OF FRUITS

\begin{tabular}{|c|c|c|c|c|c|}
\hline \multirow[b]{2}{*}{ Treatment } & \multicolumn{2}{|c|}{ External } & \multicolumn{3}{|c|}{ Internal } \\
\hline & $\begin{array}{c}\text { Peel } \\
\text { color } \\
\text { at } \\
\text { harve } \\
\text { st }\end{array}$ & $\begin{array}{c}\text { Peel } \\
\text { color at } \\
\text { ripe } \\
\text { stage }\end{array}$ & $\begin{array}{c}\text { TSS } \\
\left({ }^{\mathbf{0}} \text { Brix }\right)\end{array}$ & $\begin{array}{l}\text { Flesh } \\
\text { color }\end{array}$ & $\% \mathbf{E P}$ \\
\hline $\begin{array}{l}\text { PhilMech- } \\
\text { FiC bag }\end{array}$ & $\begin{array}{c}3.4 \pm 0 \\
05^{\mathrm{a}}\end{array}$ & $\begin{array}{c}3.3 \pm 0.1 \\
6\end{array}$ & $\begin{array}{c}7.96 \pm 0 . \\
47^{\mathrm{a}}\end{array}$ & $\begin{array}{c}3.1 \pm 0.3 \\
4\end{array}$ & $\begin{array}{c}68.57 \pm \\
0.77\end{array}$ \\
\hline $\begin{array}{l}\text { Old } \\
\text { Newspaper }\end{array}$ & $\begin{array}{c}3.2 \pm 0 \\
12^{\mathrm{a}}\end{array}$ & $\begin{array}{c}3.3 \pm 0.2 \\
2\end{array}$ & $\begin{array}{c}19.36 \pm \\
0.47^{\mathrm{b}}\end{array}$ & $\begin{array}{c}3.0 \pm 0.2 \\
5\end{array}$ & $\begin{array}{c}69.48 \pm \\
0.85\end{array}$ \\
\hline $\begin{array}{l}\text { Chinese } \\
\text { brown } \\
\text { paper }\end{array}$ & $\begin{array}{c}1.3 \pm 0 . \\
24^{b}\end{array}$ & $\begin{array}{c}3.4 \pm 0.1 \\
6\end{array}$ & $\begin{array}{c}18.89 \pm \\
0.19^{\mathrm{ab}}\end{array}$ & $\begin{array}{c}2.7 \pm 0.0 \\
9\end{array}$ & $\begin{array}{c}69.35 \pm \\
0.45\end{array}$ \\
\hline $\begin{array}{l}\text { Un-bag } \\
\text { (control) }\end{array}$ & $\begin{array}{c}3.3 \pm 0 . \\
12^{\mathrm{a}}\end{array}$ & $\begin{array}{c}3.3 \pm 0.1 \\
0\end{array}$ & $\begin{array}{l}18.77 \pm \\
0.62^{a b}\end{array}$ & $\begin{array}{c}3.0 \pm 0.1 \\
4\end{array}$ & $\begin{array}{c}67.78 \pm \\
0.94 \\
\end{array}$ \\
\hline
\end{tabular}

Means not sharing letter in common differ significantly at 0.05 level of significance by DMRT

3) Causes of non-marketability of harvested fruits: Table VI shows the causes of non-marketability of harvested mango fruits subjected to different bagging materials. The identified causes were physical damaged, insects and diseases damaged. The incidence of physical damaged was evident in un-bag fruit because fruit bagging protect the fruit from physical damage cause by strong winds and rainfall during the production stage. 
The insects observed on fruits after harvest were fruit fly, mealy bugs and scale insects. The damaged on un-bag fruits was significantly higher $(25.55 \%)$ compared to bagged fruits, particularly old newspaper $(11.11 \%)$. Incidence of high insect damage on fruit bagged using old newspaper can be attributed to the material. Old newspaper could not withstand strong winds and heavy rainfall that destroy the bags hence, greater chances for the insects to damage the fruits. No incidence of insect damage was observed on mango fruit bagged using PhilMech-FiC fruit bag and Chinese brown paper bag.

Scab and sooty molds disease were observed in the mango fruits after harvesting. The damaged cause by diseases on un-bag fruits was significantly higher (13.89\%) compared to bagged fruits, particularly old newspaper (11.11\%). Incidence of high damaged on fruit bagged using old newspaper can also attributed to the material that could not withstand strong winds and heavy rainfall that destroy the bags hence, greater chances for the insects to damage the fruits. Likewise, no incidence of disease damaged was also observed on mango fruit bagged using PhilMech-FiC fruit bag and Chinese brown paper bag.

TABLE VI

CAUSES OF NON-MARKETABILITY OF HARVESTED MANGo Fruits SUBJECTED TO DiFFERENT BAGGING MATERIALS

\begin{tabular}{|l|c|c|c|}
\hline \multirow{2}{*}{ Treatment } & \multicolumn{3}{|c|}{ Causes of non-marketability (\%) } \\
\cline { 2 - 4 } & Insects & Diseases & $\begin{array}{c}\text { Physical } \\
\text { damage }\end{array}$ \\
\hline $\begin{array}{l}\text { PhilMech-FiC } \\
\text { bag }\end{array}$ & $0.00 \pm 0.00^{\mathrm{a}}$ & $0.00 \pm 0.00$ & $0.00 \pm 0.00^{\mathrm{a}}$ \\
\hline Old Newspaper & $11.11 \pm 15.71^{\mathrm{ab}}$ & $11.11 \pm 15.71$ & $0.00 \pm 0.00^{\mathrm{a}}$ \\
\hline $\begin{array}{l}\text { Chinese brown } \\
\text { paper bag }\end{array}$ & $0.00 \pm 0.00^{\mathrm{a}}$ & $0.00 \pm 0.00$ & $0.00 \pm 0.00^{\mathrm{a}}$ \\
\hline $\begin{array}{l}\text { Un-bag } \\
\text { (control) }\end{array}$ & $25.55 \pm 6.67^{\mathrm{b}}$ & $13.89 \pm 10.39$ & $\begin{array}{c}22.22 \pm 15.71 \\
\mathrm{~b}\end{array}$ \\
\hline
\end{tabular}

\section{CONCLUSIONS}

Biodegradable fruit bag made of starch and polybutylene succinate (PBS) was developed using a twin-screw extruder and blown film extrusion machine. The PHilMech-FiC bag measured $6 \times 8$ inches with a thickness of 150 microns. The FTIR spectra of biodegradable fruit bag decreases as the amount of starch increases in the bio-composites. Moreover, AFM modulus images emphasized that reducing the amount of starch facilitated dispersal of starch inside the polymer matrix and inhibits agglomeration of the filler. The tensile strength is within the range of LDPE while the elongation is within the range of HDPE. Likewise, biodegradable film has higher density, thickness swelling and absorbed more water. It is projected that after thirty six (36) weeks, the film will be totally degraded. The quality of harvested fruits using PHilMech-FiC biodegradable fruit bag in terms of peel color at ripe stage, flesh color and percent edible portion is comparable with the existing bagging materials such as Chinese brown paper bag and old newspaper. The developed biodegradable fruit bag material will reduce the use nonbiodegradable material in the field agriculture as well as the solid waste being disposed off in landfills.

\section{ACKNOWLEDGMENT}

We would like to thank CEAT-UPLB, FiC, NMRDCGuimaras for allowing to use their laboratory, equipment and instruments, and experimental area.

\section{REFERENCES}

[1] Sriroth K., Challacup R., Piyachomkwan K. and Oates C. G. Und Biodegradable plastics from cassava starch in Thailand. Bangkok Thailand UK

[2] Scott G. 2005. Biodegradable plastics in agriculture. Aston University

[3] Zamora, N.F., R. S. Orquia and H. G. Golez. 2008. Efficiency of DuPont Tyvek ${ }^{\circledR}$ bag as bagging material for mango fruits. Bureau of Plant Industry - National Mango Research and Development Center, San Miguel, Jordan, Guimaras.

[4] Cheong K. S. et al. 2010. Development of Biodegradable Plastic Composite Blend Based on Sago Derived Starch and Natural Fiber. Pertanika Journal of Science and Technology. University of Putra Malaysia.

[5] Basilla B.A. 2011. Green Packaging Films. Industrial Technology Development Institute, DOST, Taguig City.

[6] Novamont Company. 2008. http://www.materbi.com

[7] Bio Bag. 2004. http://www.dirtworks.net/Bio-Bag1.html

[8] Lu D.R., Xiao C.M. and Xu S.J. 2009. Starch-based completely biodegradable polymer materials. Express Polymer Letters Volume 3 No. 6 366-375.

[9] Obasi H.C., and Igwe I.O. 2014. Effects of Native Cassava Starch and Compatibilizer on Biodegradable and Tensile Properties of Polypropylene. American Journal of Engineering Research (AJER) e-ISSN : 2320-0847 p-ISSN : 2320-0936 Volume-03, Issue-02, pp96-104 www.ajer.org

[10] Yossathorn T. and Jutarat P. 2015. Effect of starch types on properties of biodegradable polymer based on thermoplastic starch process by injection molding technique. Songklanakarin J. Sci. Technol. 37 (2), 193-199

[11] Gutierrez R.M., Daupan S.M.M.V., Fabian A.V. and Miclat C.C. 2015. Microbiological Investigation on Some Biodegradable Plastics used as Packaging Materials. Asian Journal of Applied Sciences (ISSN: 2321 - 0893) Volume 03

[12] Chandima A.M.B. and Jayasuriya C.K. 2015. Synthesis and characterization of biodegradable polymeric composites using locally available starch derivatives. International Journal of Scientific Research and Innovative Technology ISSN: 2313-3759 Vol. 2 No. 9

[13] Fujimaki T. 1998. Processability and properties of aliphatic polyesters "bionelle" synthesized by polycondensation reaction. Polym Degrad Stab Stab 59:209-214

[14] Flores E.D. et al. 2011. Biomass Utilization as Bio-filler for Biocomposite Materials Development. Philippine Center for Postharvest Development and Mechanization.

[15] Philippine National Standard. Code on good agricultural practices (GAP). The Bureau of Agriculture and Fisheries Standards (BAFS).

[16] Zadgaonkar A. V. 2004. Environmental Protection from Plastic Menace. Head of the Department of Applied Chemistry, G.H. Raisoni College of Engineering, Nagpur, India.

[17] Selected Statistics on Agriculture 2011. Bureau of Agricultural Statistics, Department of Agriculture, Quezon City.

[18] Kolybaba M., Tabil L.G., Panigrahi S., Crerar W.J., Powell T., Wang B. 2003. Biodegradable Polymers: Past, Present, and Future. Proceedings of CSAE/ASAE Annual Intersectional Meeting at North Dakota, USA; University of Saskatchewan, Department of Agricultural and Bioresource Engineering. p. 1-15.

[19] Vert M. 1992. Preface. Proceedings of the second international scientific workshop on biodegradable polymers and plastics, Montpellier, France. p. v-vii.

[20] Weber C.J., Haugaard V., Festersen R., and Bertelsen G. 2002. Production and applications of biobased packaging materials for the food industry. Food Addit Contam. 19: 172-177. 